\title{
Comparison of dietary trends between two counties with and without a cardiovascular prevention programme: a population- based cross-sectional study in northern Sweden
}

\author{
Johanna Törmä ${ }^{1,2, *}$, Robert Lundqvist ${ }^{3}$, Mats Eliasson $^{4}$, Lena Maria Nilsson ${ }^{5}$, \\ Viktor Oskarsson ${ }^{6}$ and Maria Wennberg ${ }^{7}$ \\ 'Department of Public Health and Caring Sciences, Health Services Research, Uppsala University, Uppsala, Sweden: \\ ${ }^{2}$ Department of Development, Region Norrbotten, Robertsviksgatan 7, SE-971 89, Luleå, Sweden: ${ }^{3}$ Department of \\ Public Health and Clinical Medicine, Sunderby Research Unit, Umeå University, Umeå, Sweden: ${ }^{4}$ Department of Public \\ Health and Clinical Medicine, Section of Medicine, Sunderby Research Unit, Umeå University, Umeå, Sweden: \\ ${ }^{5}$ Department of Epidemiology and Global Health, Umeå University, Umeå, Sweden: ${ }^{6}$ Department of Public Health and \\ Clinical Medicine, Section of Medicine, Piteå Research Unit, Umeå University, Umeå, Sweden: ${ }^{7}$ Department of Public \\ Health and Clinical Medicine, Section of Sustainable Health, Umeå University, Umeå, Sweden
}

Submitted 22 February 2021: Final revision received 24 June 2021: Accepted 14 July 2021: First published online 23 July 2021

\begin{abstract}
Objective: To compare temporal trends, over a 20-year period, in dietary habits between a county (Västerbotten) with a CVD prevention programme and a county (Norrbotten) without such a programme.

Design: Cross-sectional data from the Northern Sweden MONICA study (survey period 1994, 1999, 2004, 2009 and 2014). Dietary habits were assessed by a semi-quantitative FFQ.

Setting: Counties of Norrbotten and Västerbotten, Northern Sweden.

Participants: Five thousand four hundred Swedish adults (mean age 56.9 years; $51 \cdot 2 \%$ women) from Västerbotten (47\%) and Norrbotten ( $53 \%$ ).

Results: No differences in temporal trend for estimated percentage of energy intake from total carbohydrates, total fat, total protein and alcohol were observed between the counties $\left(P_{\text {for interaction }} \geq 0.33\right.$ ). There were no between-county difference in temporal trends for overall diet quality (assessed by the Healthy Diet Score; $P_{\text {for interaction }}=0 \cdot 36$ ). Nor were there any between-county differences for the intake of whole grain products, fruits, vegetables, fish, sweetened beverages or fried potatoes $\left(P_{\text {for interaction }} \geq 0 \cdot 09\right)$. Consumption of meat $\left(P_{\text {for interaction }}=0.05\right)$ increased to a greater extent in Norrbotten from 2009 and onwards, mainly in men (sex-specific analyses, $\left.P_{\text {for interaction }}=0.04\right)$. Men in Västerbotten decreased their intake of sweets to a greater extent than men in Norrbotten $\left(P_{\text {for interaction }}<0.01\right)$.

Conclusions: Over a 20-year period in northern Sweden, only small differences in dietary habits were observed in favour of a county with a CVD prevention programme compared with a county without such a programme.
\end{abstract}

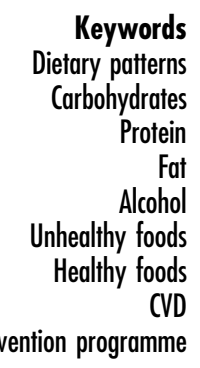

Cardiovascular disease (CVD) is the leading cause of death in the world (17.6 million deaths in 2016) ${ }^{(1)}$. To reduce this burden, a number of countries have introduced CVD prevention programmes ${ }^{(2-5)}$, with the purpose to treat conventional risk factors (i.e. hypertension, hyperlipidaemia and diabetes) and to lower the prevalence of lifestyle-related risk factors (e.g. unhealthy diet, physical inactivity and tobacco smoking).
An example of a CVD prevention programme is the Västerbotten Intervention Programme (VIP), which started in 1985 and was fully implemented in 1991 in the county of Västerbotten in northernmost Sweden ${ }^{(2)}$. Since then, more than 180000 persons have been invited to an individual health assessment and received counselling on healthy lifestyle and food habits ${ }^{(6)}$. In addition, to raise the public awareness of CVD risk factors and a healthy lifestyle, the 
involved researchers organised population-based activities in the early years of the VIP. Also, a food-labelling system for low-fat and high fibre products, which helps consumers to identify healthier food options, was developed in collaboration with the Swedish Food Agency. This food label (the green Keyhole) is still in use in the whole country (see online Supplemental Fig. 1).

Even though several evaluations of the VIP have been published $^{(7-14)}$, its effectiveness with respect to changes in risk factor profile and CVD burden is still under debate. A reduction in CVD mortality has been reported in the intervened group ${ }^{(7,15)}$; however, the spillover effect to the overall population seems to be small ${ }^{(15,16)}$. It was recently shown that among a number of risk factors, blood pressure, glucose levels and tobacco smoking had improved at a faster rate from the mid-90s in Västerbotten than in the neighbouring county of Norrbotten (that had no CVD prevention programme until 2014) ${ }^{(17)}$. However, it has not been studied whether temporal trends in dietary habits differ between Västerbotten and Norrbotten.

Using 20-year data from the Northern Sweden MONICA study, which is a population-based cohort of men and women from Västerbotten (with intervention) and Norrbotten (without intervention), we aimed to compare the changes in dietary habits between two counties with and without a CVD prevention programme.

\section{Methods}

\section{Study population}

The Northern Sweden MONICA (MONItoring of trends and determinants in CArdiovascular disease) study was initiated in $1985^{(18)}$. From its initiation up until 2014, seven population-based surveys have been conducted in Västerbotten and Norrbotten. Each survey was performed during the same months (January to April) and is an independent, cross-sectional sample of 2000 (up until 1990) to 2500 (from 1994 and onwards) randomly selected persons from population registers. The survey samples were stratified by county, sex and 10-year age group (aged 25-64 years until 1990, aged 25-74 years thereafter). Individuals answered a questionnaire on socio-demographic and lifestyle factors (e.g. sex, age and educational level), underwent a clinical examination and had blood samples drawn. They also filled in an FFQ, which, in turn, is part of the larger Northern Sweden Diet Database. The participation rate in the MONICA surveys was similar in both counties and ranged from $83 \%$ in 1994 to $64 \%$ in 2014 (for participants aged 35 to 64 years). Further details on the survey procedures are described elsewhere ${ }^{(17,18)}$.

The current study used data from the MONICA surveys in 1994 to 2014 (because the surveys prior to 1994 used a different FFQ) and was restricted to individuals aged 40 years or older (because the VIP uses that age cut-off for the intervention). Of the participants from Västerbotten county in this study, $60 \%$ had participated in the VIP prior to the participation in the MONICA study.

\section{Assessment of dietary variables}

A validated ${ }^{(19-23)}$ semi-quantitative FFQ was used to assess dietary intake. The FFQ contained eighty-four questions (food items) on a nine-point scale: ranging from 'never' to ' $>4$ times/d'. The participants also indicated portion sizes for three food groups (potatoes/rice/pasta, meat/fish and vegetables) using photo illustrations of four different portion sizes. Reported food intake frequencies were converted to $\mathrm{g} / \mathrm{d}$ based on data from a validation study ${ }^{(20)}$, and energy and nutrient intakes were estimated by multiplying food intake frequencies with portion sizes and nutrient content (the latter based on data from the Swedish Food Agency $\left.{ }^{(24)}\right)$.

Dietary macronutrients (e.g. fat, protein and carbohydrates) were calculated as percentage of energy from a nutrient (energy \% (E \%)); that is, the proportion of energy from that nutrient divided by the total energy intake. Alcohol intake was assessed by questions on five alcoholic beverages (light beer (2.3\% alcohol), medium beer $(3.5 \%$ alcohol), strong beer ( $5.4 \%$ alcohol), wine (12-13\% alcohol) and liquor/spirits (40\% alcohol)).

Overall dietary quality was assessed by the Healthy Diet Score (HDS) ${ }^{(25)}$, which in our study included eight food groups: whole grains, fish, fruits and vegetables (classified as healthy foods) and red/processed meat, sweets, sweetened beverages and fried potatoes (classified as unhealthy foods). Whole grain products included whole grain crisp bread, whole grain soft bread, oatflake/ whole wheat/rye/barley porridge and fiber cereals (e.g. muesli and granola). Fish included lean fish (e.g. perch, bass and cod), fatty fish (e.g. herring, whitefish, char and salmon) and salted fish (irrespective of type). Fruits included berries (fresh/frozen), apple, pear, peach, banana, orange and other citrus fruits. Vegetables included white cabbage, root vegetables, carrot, spinach, broccoli, kale and mixed frozen vegetables. Red/processed meat included sausage/meat/liver paté on bread, minced meat, meat stew, steak, bacon, sausage as dish, hamburger and offals. Organic meat or game/reindeer meat, the latter a common traditional, ecological and highly nutrient dense meat item, was not specified in the FFQ. Sweets included ice cream, chocolate, candy, cookies, pastry, sugar, honey and jam. Sweetened beverages included juices, nectar and sodas. Fried potatoes included fried potatoes and French fries.

HDS is study-specific, meaning that the consumption of each food group is categorised into quartiles and assigned ascending values $(0,1,2,3)$ for healthy foods, descending values $(3,2,1,0)$ for unhealthy foods and calculated for the whole cohort and separately for each sex. The values are summed up to a total score that ranges from 0 to 24 . 


\section{Statistical analyses}

Of the 6451 participants who were eligible for the current study, we excluded those with extreme energy intakes (>5000 kcal; $n$ 4) and/or extreme food intake levels (i.e. the ratio between reported energy intake and estimated BMR) ( $n$ 442). Food intake level values below the fifth and above the 97, fifth percentile were used as exclusion criteria, because under-reporting is more common than over-reporting. In addition, individuals with incomplete FFQ (i.e. missing data on portion size indications and/or missing data on $>10 \%$ of food intake frequencies) were excluded ( $n$ 605). If $<10 \%$ of food intake frequencies were missing, data were imputed for the missing variables with the median intake frequency of the same sex, 10-year age group and survey year.

Mean values of the HDS, food group consumption and macronutrient and energy intake were tabulated according to county (Västerbotten, Norrbotten) and survey year (1994, 1999, 2004, 2009 and 2014). One-way ANOVA tests were used to examine changes in dietary habits within counties. To examine whether the changes in dietary habits differed between counties, we used linear regression models that incorporated an interaction term between county and survey year (modelled as a continuous variable). All reported $P$-values in the text are for the interaction terms and were adjusted for sex, age (modelled as a continuous variable) and level of education (university, non-university). Further adjustment for BMI (BMI, modelled as a continuous variable), smoking status (current, non-current) and physical activity (almost none, 1-3 times/week and $>3$ times/week) did not change the results (data not shown). Missing data on covariates were handled by complete case analysis (total of $0.5 \%$ missing data). $P$-values $<0.05$ were considered statistically significant. SPSS version 26.0 was used for all statistical analyses (IBM Corp., IBM SPSS Statistics). The Strengthening the Reporting of Observational Studies in Epidemiology guidelines were followed whenever applicable ${ }^{(26)}$.

\section{Results}

The final study cohort included 5400 participants aged 40 to 75 years (Fig. 1), recruited between 1994 and 2014, of whom $47 \%$ were from Västerbotten (mean age 56.9 years; $49.8 \%$ women) and $53 \%$ from Norrbotten (mean age 57.0 years; $52.5 \%$ women). Socio-demographic and dietary characteristics of the study population are displayed in Table 1 . The age and sex structure of the cohort remained fairly constant over time and by county, while the proportion with a university education increased in both counties during the study period. Interestingly, reported energy intakes and estimated food intake level values decreased in both counties over time.

No differences in temporal trends for estimated percentage of energy intake from total carbohydrates

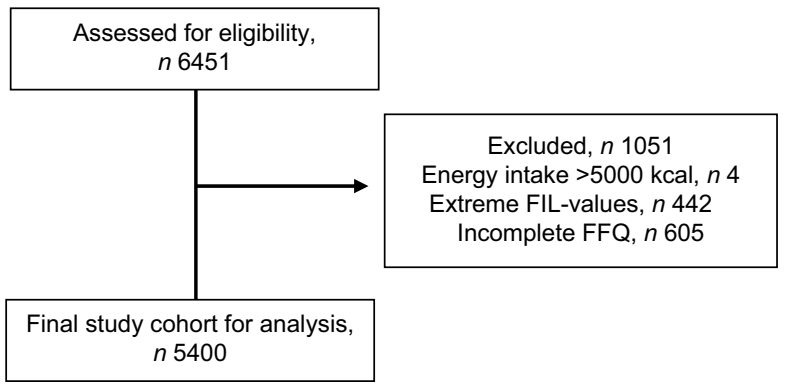

Fig. 1 Participant flow chart

$\left(P_{\text {for interaction }}=0 \cdot 40\right)$, total fat $\left(P_{\text {for interaction }}=0.33\right)$ and total protein $\left(P_{\text {for interaction }}=0.77\right)$ were observed between the counties (Fig. 2). The estimated percentage of energy from total carbohydrates declined from around 50 to $44 \mathrm{E} \%$ between 2004 and 2014, whereas that from total fat increased from around 33 to $38 \mathrm{E} \%$ during the same period. Estimated percentage of energy from total protein increased slightly from 14 to $16 \mathrm{E} \%$ between 1994 and 2014 (Table 1). The shape of the temporal associations was similar in sex-specific analyses (see online Supplemental Fig. 2a).

Estimated percentage of energy from alcohol and subtypes of carbohydrates, protein and fat did not differ between the counties and showed similar temporal trends in both counties, except for trans fats (Table 1). Estimated percentage of energy from trans fats declined between 1994 and 2004 in both counties and remained stable thereafter, but participants from Västerbotten decreased their intake of trans fats to a greater extent than those from Norrbotten $\left(P_{\text {for interaction }}=0 \cdot 02\right)$. Estimated percentage of energy from alcohol increased to a small degree up until 2009 ( $\left.P_{\text {for interaction }}=0.45\right)$. The estimated percentage of energy from saturated and monounsaturated fats increased from 2004 and onwards $\left(P_{\text {for interaction }}=0.21\right.$ and 0.68 , respectively). We observed a modest but steady increase in estimated energy from polyunsaturated fats over the entire study period $\left(P_{\text {for interaction }}=0 \cdot 74\right.$ ). From 1994 to 2014 , estimated percentage of energy intake from sugar showed a decreasing trend $\left(P_{\text {for }}\right.$ interaction $\left.=0.48\right)$. Regarding the different subtypes of protein, estimated energy from animal protein increased between 2004 and 2014, whereas estimated energy from plant protein remained stable over the entire study period ( $P_{\text {for interaction }}$ $=0.71$ and 0.79 , respectively) .

Mean values of the HDS and its included food groups by survey year and county are displayed in Table 2 . The HDS increased slightly over time, and temporal trends did not differ between the counties $\left(P_{\text {for interaction }}=0 \cdot 36\right.$, Fig. 3$)$. When looking at the healthy food items included in the HDS, no between-county differences were observed. The consumption of whole grain products decreased in both Västerbotten (from 2.8 to 2.3 servings/d) and Norrbotten (from $2 \cdot 6$ to $2 \cdot 2$ servings/d) over time 
Table 1 Socio-demographic and dietary characteristics of the study population

\begin{tabular}{|c|c|c|c|c|c|c|c|c|c|c|c|c|c|c|c|c|c|c|c|c|c|c|}
\hline \multirow{3}{*}{$\begin{array}{l}\text { County } \\
\text { Survey year }\end{array}$} & \multicolumn{11}{|c|}{ Västerbotten (n 2555) } & \multicolumn{11}{|c|}{ Norrbotten (n 2845) } \\
\hline & \multicolumn{2}{|c|}{$\begin{array}{c}1994 \\
(n 572)\end{array}$} & \multicolumn{2}{|c|}{$\begin{array}{c}1999 \\
(n 491)\end{array}$} & \multicolumn{2}{|c|}{$\begin{array}{c}2004 \\
(n 536)\end{array}$} & \multicolumn{2}{|c|}{$\begin{array}{c}2009 \\
(n 504)\end{array}$} & \multicolumn{2}{|c|}{$\begin{array}{c}2014 \\
(n 452)\end{array}$} & \multirow[b]{2}{*}{$P$} & \multicolumn{2}{|c|}{$\begin{array}{c}1994 \\
(n 613)\end{array}$} & \multicolumn{2}{|c|}{$\begin{array}{c}1999 \\
(n 628)\end{array}$} & \multicolumn{2}{|c|}{$\begin{array}{c}2004 \\
(n 605)\end{array}$} & \multicolumn{2}{|c|}{$\begin{array}{c}2009 \\
(n 493)\end{array}$} & \multicolumn{2}{|c|}{$\begin{array}{c}2014 \\
(n 506)\end{array}$} & \multirow[b]{2}{*}{$P \uparrow$} \\
\hline & Mean & SD & Mean & $\mathrm{SD}$ & Mean & SD & Mean & SD & Mean & SD & & Mean & SD & Mean & SD & Mean & SD & Mean & SD & Mean & SD & \\
\hline \multicolumn{23}{|c|}{ Socio-demographic characteristics } \\
\hline$\%$ & \multicolumn{2}{|c|}{49.3} & \multicolumn{2}{|c|}{$51 \cdot 1$} & \multicolumn{2}{|c|}{$48 \cdot 1$} & \multicolumn{2}{|c|}{$51 \cdot 2$} & \multicolumn{2}{|c|}{$49 \cdot 3$} & ns & \multicolumn{2}{|c|}{$51 \cdot 2$} & \multicolumn{2}{|c|}{51.9} & \multicolumn{2}{|c|}{52.9} & \multicolumn{2}{|c|}{$52 \cdot 3$} & \multicolumn{2}{|c|}{$54 \cdot 3$} & $\mathrm{~ns}$ \\
\hline $\begin{array}{l}\text { Age } \\
\text { University education }\end{array}$ & $56 \cdot 6$ & 9.7 & $56 \cdot 7$ & 9.7 & $57 \cdot 6$ & $9 \cdot 6$ & $56 \cdot 6$ & $9 \cdot 7$ & $57 \cdot 1$ & $9 \cdot 7$ & ns & $56 \cdot 2$ & $9 \cdot 3$ & 56.9 & 9.8 & $57 \cdot 2$ & 9.7 & $57 \cdot 4$ & $9 \cdot 4$ & $57 \cdot 2$ & $9 \cdot 4$ & ns \\
\hline $\begin{array}{c}\% \\
\text { Dietary characteristics }\end{array}$ & \multicolumn{2}{|c|}{$13 \cdot 8$} & 24 & & 23 & & 29 & & 36 & & $* \star *$ & 18 & & 17 & & 21 & & 26 & & 33 & & *** \\
\hline Energy intake (kcal) & 1740 & 546 & 1710 & 516 & 1689 & 515 & 1625 & 497 & 1619 & 541 & $* \star *$ & 1632 & 548 & 1671 & 484 & 1589 & 518 & 1564 & 503 & 1545 & 527 & 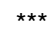 \\
\hline Food intake level (FIL) & $1 \cdot 10$ & 0.29 & 1.08 & 0.30 & 1.06 & 0.29 & 1.01 & 0.28 & 1.00 & 0.30 & $\star \star \star *$ & 1.03 & 0.31 & 1.06 & 0.29 & 1.00 & 0.29 & 0.98 & 0.29 & 0.96 & 0.28 & $\star \star * *$ \\
\hline Percentage of energy ir & take & & & & & & & & & & & & & & & & & & & & & \\
\hline Total fat & $32 \cdot 8$ & 5.4 & 33.3 & $6 \cdot 0$ & $32 \cdot 7$ & $5 \cdot 8$ & $35 \cdot 0$ & 6.5 & $38 \cdot 1$ & $7 \cdot 0$ & $* \star *$ & $33 \cdot 0$ & $6 \cdot 3$ & 33.5 & $6 \cdot 3$ & 32.4 & $6 \cdot 3$ & $35 \cdot 8$ & $6 \cdot 7$ & $38 \cdot 3$ & $7 \cdot 1$ & $* \star \star *$ \\
\hline Total carbohydrates & $50 \cdot 9$ & $5 \cdot 6$ & 50.4 & $5 \cdot 8$ & $50 \cdot 1$ & $6 \cdot 1$ & $47 \cdot 4$ & $6 \cdot 6$ & 44.0 & $7 \cdot 8$ & 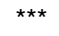 & $50 \cdot 7$ & 6.5 & $50 \cdot 2$ & 6.5 & $50 \cdot 6$ & $6 \cdot 6$ & 46.9 & $7 \cdot 1$ & $43 \cdot 6$ & $7 \cdot 7$ & 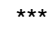 \\
\hline Total protein & 14.4 & $2 \cdot 0$ & 14.4 & $2 \cdot 0$ & $14 \cdot 8$ & $2 \cdot 2$ & $15 \cdot 2$ & $2 \cdot 3$ & $15 \cdot 6$ & $2 \cdot 6$ & $* \star *$ & 14.5 & $2 \cdot 2$ & 14.5 & 2.5 & 14.9 & 2.4 & $15 \cdot 0$ & 2.5 & $15 \cdot 9$ & 2.9 & 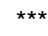 \\
\hline Saturated fat & 14.4 & $3 \cdot 2$ & $14 \cdot 1$ & $3 \cdot 3$ & $13 \cdot 6$ & $3 \cdot 1$ & $14 \cdot 7$ & 3.4 & $16 \cdot 2$ & $3 \cdot 8$ & $* \star *$ & $14 \cdot 6$ & 3.7 & $14 \cdot 2$ & 3.4 & 13.4 & 3.5 & $15 \cdot 1$ & 3.6 & $16 \cdot 5$ & 4.0 & $* \star *$ \\
\hline Trans fat & 1.4 & 0.4 & 0.9 & 0.3 & 0.5 & 0.2 & 0.6 & 0.2 & 0.6 & 0.2 & $\star \star \star *$ & 1.3 & 0.4 & 0.9 & 0.3 & 0.5 & 0.2 & 0.6 & 0.2 & 0.6 & 0.2 & 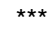 \\
\hline Monounsaturated fat & $10 \cdot 9$ & $2 \cdot 0$ & $11 \cdot 1$ & $2 \cdot 2$ & 11.0 & $2 \cdot 3$ & 11.8 & 2.5 & $12 \cdot 7$ & $2 \cdot \overline{6}$ & $\star \star \star *$ & $10 \cdot 9$ & $2 \cdot 3$ & 11.3 & 2.3 & $10 \cdot 8$ & $2 \cdot 3$ & $12 \cdot 0$ & $2 \cdot \overline{5}$ & $12 \cdot 8$ & $2 \cdot 6$ & 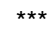 \\
\hline Polyunsaturated fat & 4.4 & $1 \cdot 2$ & $5 \cdot 1$ & 1.9 & $5 \cdot 2$ & 1.6 & 5.5 & 1.9 & $5 \cdot 8$ & 1.9 & 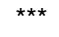 & 4.4 & $1 \cdot 2$ & $5 \cdot 1$ & 1.9 & $5 \cdot 3$ & $2 \cdot 0$ & $5 \cdot 6$ & 1.9 & $5 \cdot 8$ & $2 \cdot 1$ & 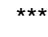 \\
\hline Sugar & 8.2 & 3.4 & 8.0 & 3.6 & 7.4 & 3.3 & $6 \cdot 6$ & $3 \cdot 1$ & $6 \cdot 1$ & $3 \cdot 1$ & $\star \star \star *$ & 8.4 & $4 \cdot 1$ & 8.2 & 4.0 & 7.5 & 3.8 & 6.9 & 3.6 & $6 \cdot 1$ & 3.0 & 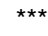 \\
\hline Animal protein & $10 \cdot 0$ & $2 \cdot 2$ & $10 \cdot 0$ & $2 \cdot 2$ & $10 \cdot 3$ & 2.4 & $10 \cdot 9$ & 2.5 & 11.6 & 3.0 & $* \star *$ & $10 \cdot 1$ & 2.4 & $10 \cdot \overline{3}$ & 2.5 & 10.4 & $2 \cdot 6$ & $10 \cdot 8$ & $2 \cdot 7$ & $12 \cdot 0$ & $3 \cdot 1$ & 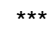 \\
\hline Plant protein & 4.4 & 0.9 & 4.4 & 0.9 & 4.5 & 0.9 & $4 \cdot 3$ & 0.9 & 4.0 & $1 \cdot 1$ & $* * *$ & 4.4 & 1.0 & 4.3 & 1.0 & 4.5 & $1 \cdot 1$ & $4 \cdot 2$ & 1.0 & 4.0 & $1 \cdot 1$ & $* \star *$ \\
\hline Alcohol & 1.4 & 1.7 & 1.5 & 1.8 & $2 \cdot 0$ & $2 \cdot 2$ & $2 \cdot 0$ & $2 \cdot 3$ & $2 \cdot 1$ & $2 \cdot 6$ & $\star \star \star *$ & 1.3 & 1.9 & 1.4 & $2 \cdot 1$ & 1.7 & $2 \cdot 1$ & $2 \cdot 0$ & $2 \cdot 2$ & 1.8 & $2 \cdot 2$ & 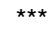 \\
\hline
\end{tabular}

ns, non-significant.

†ANOVA (continuous variables) and $\chi^{2}$ (categorical variables) tests for within-county differences. 
Diet and cardiovascular prevention programme

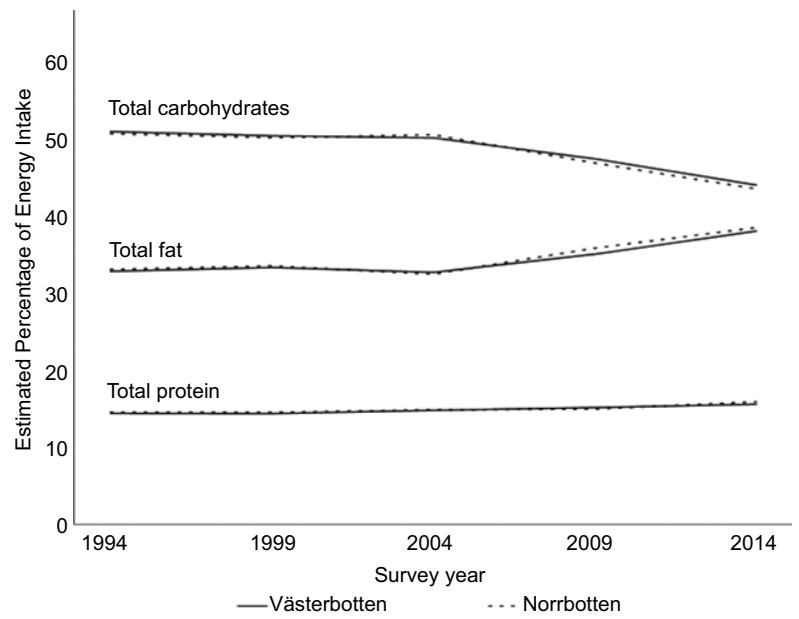

Fig. 2 Temporal trends of unadjusted mean values of estimated percentage of energy intake from total carbohydrates, total fat and protein, 1994-2014

( $\left.P_{\text {for interaction }}=0.09\right)$, while the consumption of fruits, veg- etables and fish remained rather stable in both counties

( $P_{\text {for interaction }}=0.97,0.57$ and 0.58 , respectively) (Fig. 4).

Regarding the unhealthy food items, the consumption of sweets decreased to a similar extent in both counties over time ( $P_{\text {for interaction }}=0.24$ ), while the consumption of sweetened beverages and fried potatoes remained fairly stable $\left(P_{\text {for }}\right.$ interaction $=0.18$ and 0.49 , respectively) (Fig. 5). Albeit only borderline statistically significant $\left(P_{\text {for interaction }}\right.$ $=0.052$ ), the consumption of red/processed meat seemed to increase to a greater extent in Norrbotten than Västerbotten from 2009 and onwards.

The sex-specific temporal associations of the HDS and its components were similar to that of the pooled population (see online Supplemental Fig. 2b, 2c and 2d), with the exception for the male-specific consumption of red/processed meat and sweets. Men in Norrbotten increased their consumption of red/processed meat and men in Västerbotten decreased their intake of sweets to a greater extent than their counterparts in the other county $\left(P_{\text {for inter- }}\right.$ action $=0.04$ and $<0.01$, respectively).

\section{Discussion}

In this population-based cross-sectional study of Swedish men and women, we only observed small temporal differences in dietary habits in favour of a county with (Västerbotten) compared with a county without (Norrbotten) a CVD prevention programme. Thus, the better development in some CVD risk factors in Västerbotten compared with Norrbotten, as reported by previous research ${ }^{(17)}$, can only partly be explained by differences in diet.

During the 20-year study period (1994 to 2014), irrespective of county, the intake of total carbohydrates

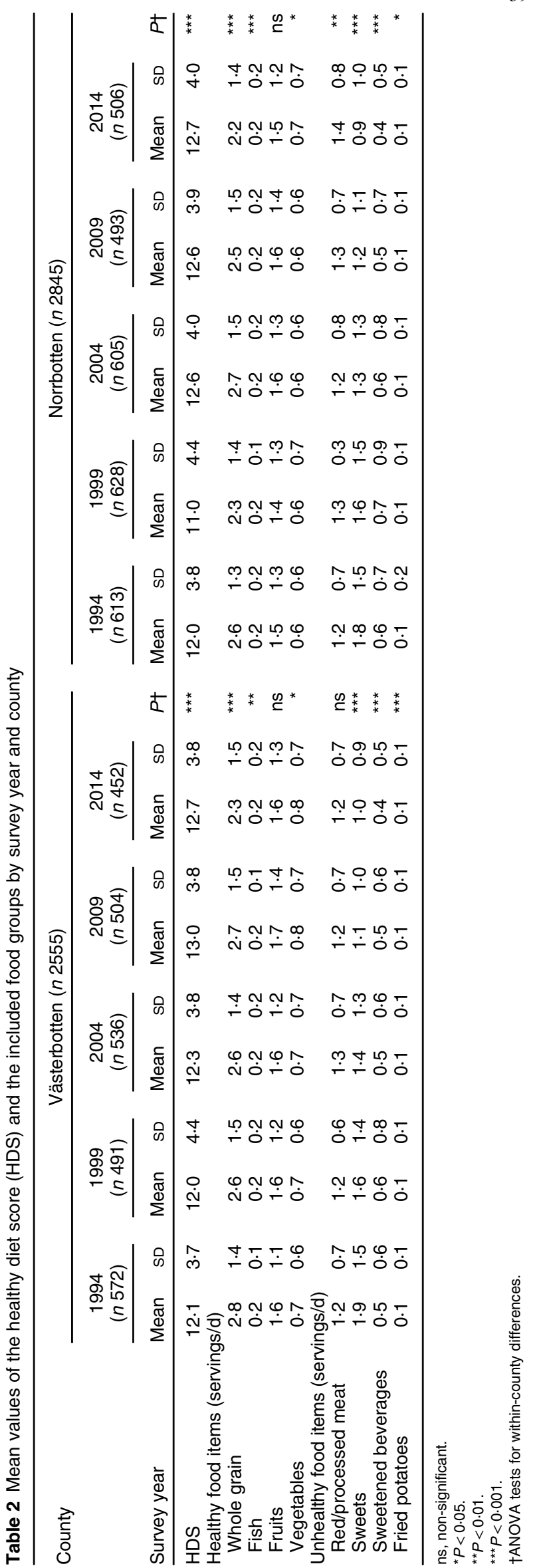




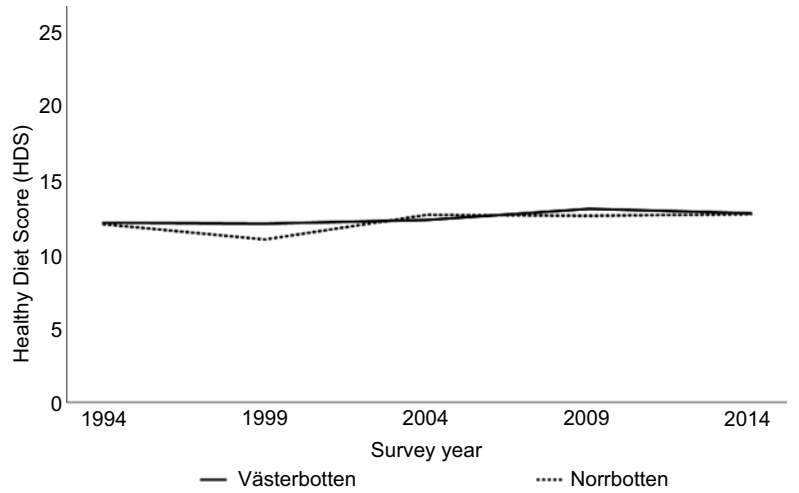

Fig. 3 Temporal trends of unadjusted mean values of Healthy Diet Score (HDS), 1994-2014

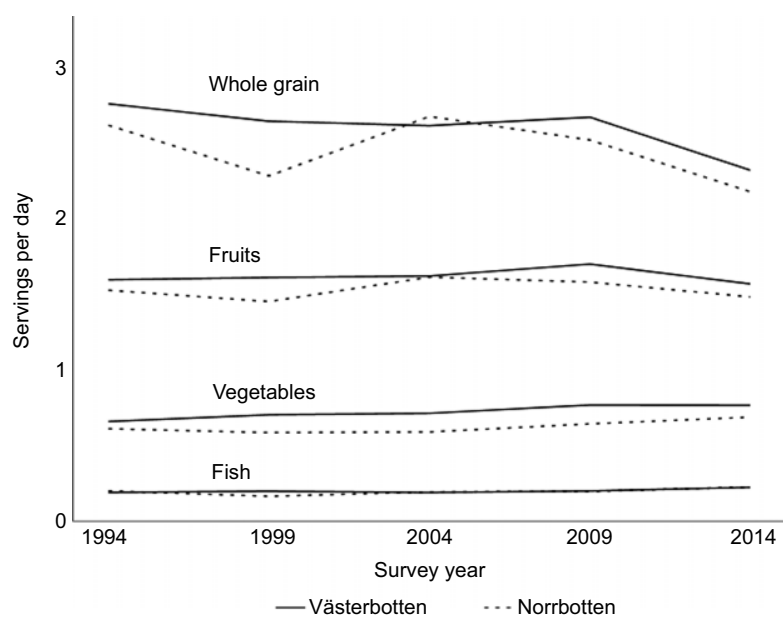

Fig. 4 Temporal trend of unadjusted mean values of healthy food items, 1994-2014

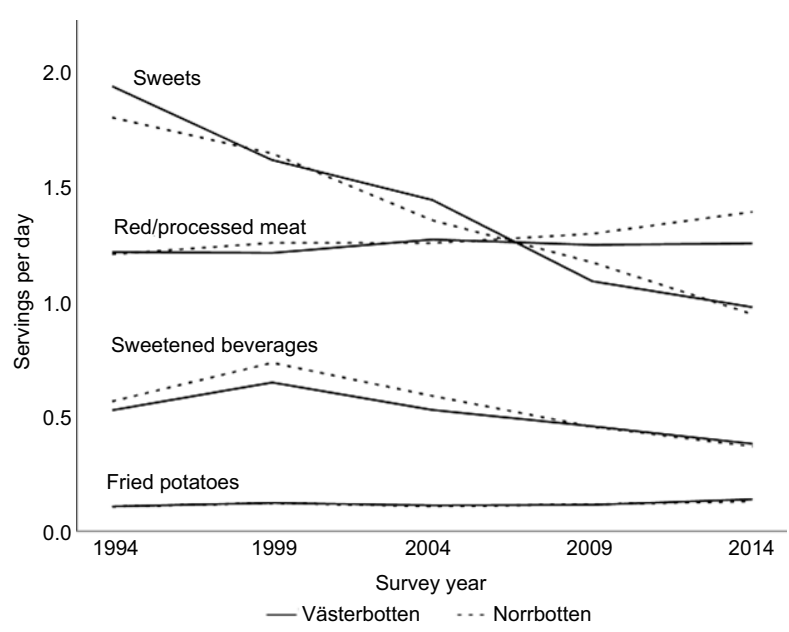

Fig. 5 Temporal trend of unadjusted mean values of unhealthy food items, 1994-2014

decreased, that of total fats increased and that of total protein remained stable. The temporal trends of intake of carbohydrates, fats and protein in our study are in line with a previous study on dietary trends in northern Sweden between 1986 and 2010, which included dietary data from participants in both the VIP and the Northern Sweden MONICA study (90\% from the VIP) ${ }^{(27)}$. The only fat subtype for which we observed a decrease was trans fat. The decrease seen in both counties is most likely due to the reduced use of partially hydrogenated fats in foods since the mid-1990s.

In recent years, an increased intake of fats and a decreased intake of carbohydrates have also been observed in the official statistics of food consumption in Sweden ${ }^{(28)}$. In addition, the North Karelia Project in Finland, which is another CVD prevention programme, reported that the fat intake decreased up until 2007, after which it started to increase again ${ }^{(29)}$. It is reasonable to assume that the ongoing nutritional debate about different low-carbohydrate-high-fat diets has had an impact on these results.

There has recently been a shift in nutritional research from macronutrient quantity to macronutrient quality ${ }^{(30,31)}$; that is, a focus on high-quality carbohydrates (e.g. whole grain) and high-quality fats (i.e. unsaturated fats) instead of the fat-to-carbohydrate ratio. This is also emphasised in the official Nordic nutritional guidelines ${ }^{(32)}$, and a newly published cohort study - using data from the US National Health and Nutrition Examination Survey of 37233 adults showed that it was not the fat-to-carbohydrate ratio of a diet that was associated with total mortality but rather the type of fats and carbohydrates that was included in the diet ${ }^{(33)}$.

The HDS was used to assess overall diet quality, and it increased slightly over time but did not differ between the counties. Temporal changes were observed for some food groups, such as whole grain products, sweets and red/ processed meat, and there were some small betweencounty differences. Consumption of whole grain products decreased in both counties, which is not in line with a healthy dietary pattern. Consumption of sweets decreased in both counties, but men in Västerbotten decreased their consumption more than men in Norrbotten. Consumption of meat increased to a greater extent in Norrbotten from 2009 and onward, mainly attributable to differences in men. The consumption of red/processed meat should be limited to $500 \mathrm{~g} /$ week, that is, 4 meals a week according to the Nordic nutritional guidelines ${ }^{(32)}$. Our data indicate consumption of on average 1 serving/d in both counties. Although meat contains vital nutrients (e.g. protein, Fe and vitamin $\mathrm{B}_{12}$ ), the consumption is still too high compared with the recommendations, and a decrease in the population would be beneficial for public health.

The significant difference in estimated energy percentage from trans fats in favour of Västerbotten may partly be explained by the male-specific differences in intakes of red/processed meat and sweets, which, in turn, might have contributed to the better outcomes in blood pressure and fasting glucose previously observed in Västerbotten compared with Norrbotten ${ }^{(17)}$. 
The diet intervention in the VIP has been modified somewhat over the years, but the main message is to reduce total fats, change saturated fats to polyunsaturated fats and eat more vegetables, legumes, fruit, fish and whole grain. In contrast to the recommendations, we observed increased intakes of total and saturated fats and decreased consumption of whole grain products by the end of the study period in Västerbotten and Norrbotten alike. These trends indicate that additional strategies and collaborations between different public health sectors are needed to change the general population's dietary habits. In addition, a more balanced debate about different diets and their health effects is desirable.

Recently, the effectiveness of health checks has been up for debate. One Cochrane review, including fourteen trials, concluded that general health checks did not reduce mortality or morbidity ${ }^{(34)}$. This review was recently updated ${ }^{(35)}$, now including seventeen trials, and came to the same conclusion. Another review and meta-analysis, including six trials, focused on general practice-based health checks and surrogate outcomes, and it showed that the health checks led to improvements in total cholesterol, blood pressure and $\mathrm{BMI}^{(36)}$. As mentioned earlier, the VIP has also been subject to evaluation. The prevalence of some cardiovascular risk factors (i.e. blood pressure, fasting glucose levels and smoking cessation) was found to be in favour of the programme in a recent study ${ }^{(17)}$, which had an identical study design and was performed in the same cohort as the current study. As for other lifestyle-related variables, such as physical activity and BMI, the temporal development was fairly similar in the two counties ${ }^{(17)}$. However, based on our study, the observed differences in some CVD risk factors in favour of the VIP only seem to be explained by beneficial dietary changes to a small extent. An interesting observation in our study was that the energy percentage from total and saturated fats increased from 2004 and onward, despite that the cohort's cholesterol levels have decreased steadily throughout the study period (1994-2014) ${ }^{(17)}$. This is in contrast to previous studies from northern Sweden and Finland ${ }^{(27,29)}$, where time periods with increased intakes of total and saturated fats have led to increased cholesterol levels (and vice versa, for time periods with decreased intakes). A possible explanation to the finding in the present study could be an increased prescription of cholesterol-lowering drugs as a result of expired patents for these drugs during the study period.

Lifestyle modifications are known to be challenging and require a great deal of efforts from both the intervened individuals and the health professionals. A number of barriers to achieve and maintain weight loss and to stay physically active have been described ${ }^{(37,38)}$, and it is likely that the same barriers apply for dietary changes. It could be that occasional health checks combined with individual counselling about healthy lifestyle habits, including diet, are not enough and that more efforts and resources, and possibly other methods, are needed to achieve sustainable changes in diet. A recently published study suggested that health care intervention programmes aimed at reducing obesity should adopt a team based and more comprehensive and holistic approach to be successful ${ }^{(39)}$. Furthermore, the National Institute for Health and Care Excellence in the UK has published guidelines in effective behaviour change that can be incorporated in standard health and social care practice ${ }^{(40)}$.

\section{Methodological concerns}

A strength of the present study is the population-based sample with measurements over a period of 20 years, together with the fairly high participation rate. Another strength is that the Northern Sweden MONICA study is conducted in two neighbouring counties with similar socioeconomic and demographic characteristics. This enables evaluations of the VIP, although not in a randomised design, by comparing time trends between two counties that share comparable features but differs in the implementation of a CVD prevention programme.

Several limitations must also be mentioned. First, the actual participation in the VIP in our cohort was $60 \%$. Therefore, we studied both the direct and indirect effect of the VIP on dietary changes. Second, as with all methods of self-reported dietary intake, the FFQ had inherent sources of error. To address potential measurement errors, several validation studies have been published, with the conclusion that the FFQ used in the Northern Sweden MONICA study has a good reproducibility and a validity similar to that of FFQ in other prospective cohort studies $^{(20,21)}$. Recall bias is of special concern with FFQ, since individuals have to report their dietary intakes retrospectively for a long period of time. Another concern is underreporting due to social desirability bias, meaning that individuals intentionally misreport their intakes of certain foods. It is, however, unlikely that the degree of recall and social desirability bias should have varied substantially between counties. A FFQ is also, by design, restricted to the food items that are listed in the questionnaire. In all five surveys in our study (1994, 1999, 2004, 2009 and 2014), an identical FFQ was used. While this made it easy to compare the data, it did not capture the increased diversity of food sources over time. For example, the FFQ did not include vegetarian/plant-based food items, so whether there was a between-county difference in these food items could not be answered by the present study. New food items available at the market over time, not captured by the FFQ, are a likely explanation to the observed decrease in energy intake and food intake level over time. Thus, there might have been dietary differences between the counties that we did not manage to capture with the FFQ. 


\section{Conclusions}

Over a 20-year period in northern Sweden, only small differences in dietary habits were observed in favour of a county with a CVD prevention programme compared with a county without such a programme. Further studies are needed to examine the impact of CVD prevention programmes with respect to sustainable dietary changes.

\section{Acknowledgements}

Acknowledgements: This work was supported by Norrbotten and Västerbotten County Council and the Joint Committee of the County Councils in Northern Sweden. We acknowledge the Swedish Research Council for support in building up the diet database. Financial support: This research received no specific grant from any funding agency, commercial or not-for-profit sectors. Conflict of interest: There are no conflicts of interest. Authorship: J.T., M.W., L.M.N. and M.E. designed the study. M.E. contributed with data collection as previous principal investigator of the Northern Sweden MONICA study in Norrbotten. Statistical analyses were performed by J.T. with support from R.L. and V.O. All authors contributed to the interpretation of the results. J.T. drafted the manuscript. R.L., M.E., L.M.N., V.O. and M.W. reviewed and revised the manuscript. The final version was read and approved by all authors. Ethics of buman subject participation: This study was conducted according to the guidelines laid down in the Declaration of Helsinki, and all procedures involving research study participants were approved by the Regional Ethical Committee at Umeå University (Umeå, Sweden). The Northern Sweden MONICA study has been covered by several ethical approvals between 1986 and 2013 and the latest with reference number 2013/97-31. Written informed consent was obtained from all subjects/patients.

\section{Supplementary material}

For supplementary material accompanying this paper visit https://doi.org/10.1017/S1368980021003050

\section{References}

1. Benjamin EJ, Muntner P, Alonso A et al. (2019) Heart disease and stroke statistics-2019 update: a report from the American Heart Association. Circulation 139, e56-e528.

2. Norberg M, Wall S, Boman K et al. (2019) The Västerbotten intervention programme: background, design and implications. Glob Health Action 3, Suppl. 4, 4643.

3. NHS Health Check (2019) NHS Health Check Best Practice Guidance. https://www.healthcheck.nhs.uk/ commissioners-and-providers/national-guidance/ (accessed August 2020)

4. Jorgensen T, Borch-Johnsen K, Thomsen TF et al. (2003) A randomized non-pharmacological intervention study for prevention of ischaemic heart disease: baseline results Inter99. Eur J Cardiovasc Prev Rehabil 10, 377-386.

5. Record NB, Onion DK, Prior RE et al. (2015) Communitywide cardiovascular disease prevention programs and health outcomes in a rural county, 1970-2010. JAMA 313, 147-155.

6. Region Västerbotten (2019) Västerbotten Intervention Programme. https://regionvasterbotten.se/forskning/ vasterbotten-intervention-programme (accessed February 2020).

7. Weinehall L, Hellsten G, Boman K et al. (2001) Can a sustainable community intervention reduce the health gap? 10-year evaluation of a Swedish community intervention program for the prevention of cardiovascular disease. Scand J Public Health Suppl 56, 59-68.

8. Norberg M, Blomstedt Y, Lonnberg G et al. (2012) Community participation and sustainability-evidence over 25 years in the Västerbotten intervention programme. Glob Health Action 5 (Suppl. 6), 19166.

9. Norberg M, Lindvall K, Stenlund H et al. (2010) The obesity epidemic slows among the middle-aged population in Sweden while the socioeconomic gap widens. Glob Health Action 3 (Suppl. 4), 5149.

10. Norberg M, Lundqvist G, Nilsson M et al. (2011) Changing patterns of tobacco use in a middle-aged population: the role of snus, gender, age, and education. Glob Health Action 4 (Suppl. 3), 5613.

11. Ng N, Carlberg B, Weinehall L et al. (2012) Trends of blood pressure levels and management in Västerbotten County, Sweden, during 1990-2010. Glob Health Action 5 (Suppl. 6), 18195.

12. Ng N, Soderman K, Norberg M et al. (2011) Increasing physical activity, but persisting social gaps among middle-aged people: trends in northern Sweden from 1990 to 2007. Glob Health Action 4 (Suppl. 3), 6347.

13. Lindholm L, Stenling A, Norberg M et al. (2018) A cost-effectiveness analysis of a community based CVD program in Sweden based on a retrospective register cohort. BMC Public Health 18, 452.

14. Long GH, Simmons RK, Norberg M et al. (2014) Temporal shifts in cardiovascular risk factor distribution. Am J Prev Med 46, 112-121.

15. Blomstedt $\mathrm{Y}$, Norberg M, Stenlund $\mathrm{H}$ et al. (2015) Impact of a combined community and primary care prevention strategy on all-cause and cardiovascular mortality: a cohort analysis based on 1 million person-years of follow-up in Västerbotten County, Sweden, during 1990-2006. BMJ Open 5, e009651.

16. San Sebastian M, Mosquera PA \& Gustafsson PE (2019) Do cardiovascular disease prevention programs in northern Sweden impact on population health? An interrupted time series analysis. BMC Public Health 19, 202.

17. Eliasson M, Eriksson M, Lundqvist Ret al. (2018) Comparison of trends in cardiovascular risk factors between two regions with and without a community and primary care prevention programme. Eur J Prev Cardiol 25, 1765-1772.

18. Stegmayr B, Lundberg V \& Asplund K (2003) The events registration and survey procedures in the northern Sweden MONICA project. Scand J Public Health Suppl 61, 9-17.

19. Johansson G, Wikman A, Ahren AM et al. (2001) Underreporting of energy intake in repeated 24-h recalls related to gender, age, weight status, day of interview, educational level, reported food intake, smoking habits and area of living. Public Health Nutr 4, 919-927.

20. Johansson I, Hallmans G, Wikman A et al. (2002) Validation and calibration of food-frequency questionnaire 
measurements in the northern Sweden health and disease cohort. Public Health Nutr 5, 487-496.

21. Wennberg M, Vessby B \& Johansson I (2009) Evaluation of relative intake of fatty acids according to the northern Sweden FFQ with fatty acid levels in erythrocyte membranes as biomarkers. Public Health Nutr 12, 1477-1484.

22. Johansson I, Van Guelpen B, Hultdin J et al. (2010) Validity of food frequency questionnaire estimated intakes of folate and other B vitamins in a region without folic acid fortification. Eur J Clin Nutr 64, 905-913.

23. Klingberg S, Winkvist A, Hallmans G et al. (2013) Evaluation of plant sterol intake estimated with the northern Sweden FFQ. Public Health Nutr 16, 460-467.

24. Swedish Food Agency National food database (2011). http:// www7.slv.se/SokNaringsinnehall (accessed February 2020).

25. Nettleton JA, Hivert MF, Lemaitre RN et al. (2013) Metaanalysis investigating associations between healthy diet and fasting glucose and insulin levels and modification by loci associated with glucose homeostasis in data from 15 cohorts. Am J Epidemiol 177, 103-115.

26. von Elm E, Altman DG, Egger M et al. (2014) The strengthening the reporting of observational studies in epidemiology (STROBE) statement: guidelines for reporting observational studies. Int J Surg 12, 1495-1499.

27. Johansson I, Nilsson LM, Stegmayr B et al. (2012) Associations among 25-year trends in diet, cholesterol and BMI from 140,000 observations in men and women in northern Sweden. Nutr J 11, 40

28. Lööv H, Widell LM \& Sköld O (2015) Livsmedelskonsumtionen i Siffror - Hur Har Konsumtionen Utvecklats de Senaste Femtio Aren Och Varför? (Food consumption in Numbers - How has the Consumption Evolved in the Last Fifty Years and Why?). Jönköping: Swedish Board of Agriculture.

29. Vartiainen E, Laatikainen T, Tapanainen H et al. (2016) Changes in serum cholesterol and diet in north Karelia and all Finland. Glob Heart 11, 179-184.
30. Ludwig DS, Hu FB, Tappy L et al. (2018) Dietary carbohydrates: role of quality and quantity in chronic disease. BMJ 361, k2340.

31. Ludwig DS, Willett WC, Volek JS et al. (2018) Dietary fat: from foe to friend? Science 362, 764-770.

32. Nordic Council (2004) Nordic Nutrition Recommendations: Integrating Nutrition and Physical Activity. Copenhagen: Nordic Council of Ministers.

33. Shan Z, Guo Y, Hu FB et al. (2020) Association of low-carbohydrate and low-fat diets with mortality among US adults. JAMA Intern Med 180, 513-523.

34. Krogsboll LT, Jorgensen KJ, Gronhoj Larsen C et al. (2012) General health checks in adults for reducing morbidity and mortality from disease: Cochrane systematic review and meta-analysis. BMJ 345, e7191.

35. Krogsboll LT, Jorgensen KJ \& Gotzsche PC (2019) General health checks in adults for reducing morbidity and mortality from disease. Cochrane Database Syst Rev issue 1, CD009009.

36. Si S, Moss JR, Sullivan TR et al. (2014) Effectiveness of general practice-based health checks: a systematic review and meta-analysis. Br J Gen Pract 64, 47.

37. Venditti EM, Wylie-Rosett J, Delahanty LM et al. (2014) Short and long-term lifestyle coaching approaches used to address diverse participant barriers to weight loss and physical activity adherence. Int J Behav Nutr Phys Act 11, 16.

38. Metzgar CJ, Preston AG, Miller DL et al. (2015) Facilitators and barriers to weight loss and weight loss maintenance: a qualitative exploration. J Hum Nutr Diet 28, 593-603.

39. Mandlik M, Oetzel JG \& Kadirov D (2021) Obesity and health care interventions: substantiating a multi-modal challenge through the lens of grounded theory. Health Promot $J$ Austr 32, 274-284.

40. National Institute for Health and Care Excellence (2014) Behaviour change: individual approaches. https://www. nice.org.uk/guidance/ph49 (accessed August 2020). 